\title{
The morphometric study of the jugular foramen in human adult skulls of Western Maharashtra
}

\author{
Avinash D Shewale ${ }^{1}$, Swati Lalasaheb Patil ${ }^{2 *}$, Rohini Rajesh Karambelkar ${ }^{3}$ \\ ${ }^{1}$ Associate Professor, ${ }^{2}$ Assistant Professor, ${ }^{3}$ Professor and HOD, Department of Anatomy, Prakash Institute of Medical Sciences and \\ Research, Islampur, Sangali ,M aharashtra, INDIA. \\ Email: drswatipatil1612@gmail.com
}

$\underline{\text { Abstract }}$

\begin{abstract}
Aims and objectives: To study and compare the anthropometric measurements of jugular foramina in human adult skulls of Western Maharashtra. Material and methods: This study was carried out on 100 dry skulls with 65 male and 35 female skulls in the Department of Anatomy, Prakash Institute of Medical Sciences and Research, Islampur. Digital vernier caliper was used to take the jugular foramen measurements of both sides. Parameters were length and width of jugular foramen. The data was analysed by using SPSS version 16.0. Observation and results: All the parameters were significantly larger on right side than left one in both males and females which was statistically significant. Conclusion: The measurements of bilateral jugular foramen of males and females obtained in the study may be helpful for neurosurgeons, radiologists and forensic experts as it contain significant vessels and neural structure
\end{abstract}

Key Word: morphometry, jugular foramen, neurosurgeon

*Address for Correspondence:

Dr. Swati Lalasaheb Patil, Assistant Professor, Department of Anatomy, Prakash Institute of Medical Sciences and Research, Islampur,

Sangali, Maharashtra, INDIA.

Email: drswatipatil1612@ gmail.com

Received Date: 14/06/2018 Revised Date: 20/07/2018 Accepted Date: 16/08/2018

DOI: https://doi.org/10.26611/1001721

\begin{tabular}{|l|l|}
\hline \multicolumn{2}{|c|}{ Access this article online } \\
\hline Quick Response Code: & Website: \\
\hline & www.medpulse.in \\
\hline
\end{tabular}

\section{INTRODUCTION}

The jugular foramen is a depression located at the posterior end of the petro-occipital suture. It is formed by the petrous temporal bone anterolaterally and the occipital bone posteromedially. It courses anteriorly then laterally and finally inferiorly through skull base ${ }^{1}$. It consists of a smaller anteromedial portion (pars nervosa) and a larger posterolateral portion (pars vascularis) that are separated by a complete or incomplete fibrous or bony septum. The pars nervosa contains the glossopharyngeal nerve and inferior petrosal sinus. The pars vascularis contains the internal jugular vein, the vagus nerve and spinal part of accessory nerve. Within the jugular foramen glossopharyngeal nerve gives off the tympanic branch called the nerve of Jacobson and the auricular branch of vagus nerve i.e. Arnold's nerve ${ }^{2}$. The jugular foramen is separated from the hypotympanum by a bony plate and is medial to the descending facial canal. It is separated from the anteromedial carotid canal by the caroticojugular spine and from the inferomedial hypoglossal canal by the jugular tubercle. The sigmoid sinus courses anteriorly into the jugular bulb ${ }^{3}$. The jugular foramen varies in size and shape in different crania, from side to side in the same cranium, from its intracranial to extracranial end in the same foramen because of its complex irregular shape, its curved course and its formation by two bones. It is generally said that the size, height and volume of jugular foramen vary in different racial groups and sexes $4^{, 5}$. It is important to know the morphology of the jugular foramen because intracranial and extracranial lesions may affect the jugular foramen in addition to intrinsic abnormalities.

\section{MATERIALS AND METHODS}

Total 200 jugular foramina were examined from 100 adult dry skulls with known male and female differentiation. The skulls were obtained from the department of Anatomy, Prakash Institute of Medical 
Sciences and Research, Islampur. The length, width, and presence or absence of bony septum was observed. The measurements were taken by using sliding digital vernier caliper. A comparison was made by means of the dimensions using paired $\mathrm{t}$ test. The mean, standard deviation and range of each dimension was calculated. Right and left side differences in male and female skulls were analysed.

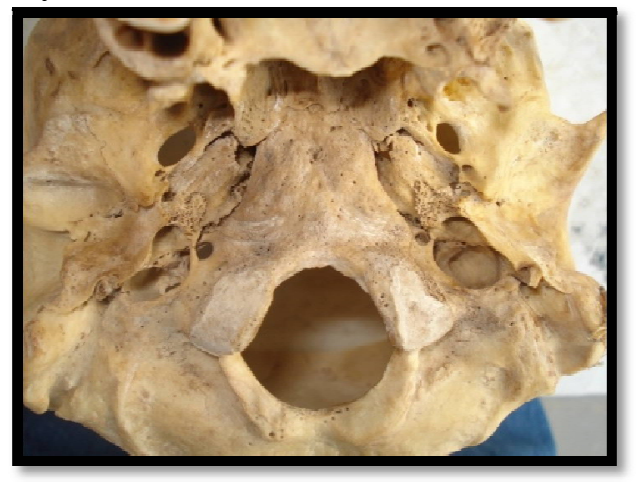

Figure 1: Arrow showing jugular foramen in dry skull

\section{OBSERVATIONS AND RESULTS:}

Table No 1: Comparison of male right vs female right jugular

\begin{tabular}{ccccc} 
Variables & $\begin{array}{c}\text { Jugular Foramen } \\
\text { length }\end{array}$ & \multicolumn{2}{c}{ Jugular foramen width } \\
& M & $\mathrm{F}$ & $\mathrm{M}$ & $\mathrm{F}$ \\
Mean & 1.75 & 1.71 & 0.98 & 0.93 \\
S.D. & 0.23 & 0.18 & 0.20 & 0.23 \\
t value & 0.89 & & & 0.94 \\
p value & 0.02 & & & 0.70 \\
\hline
\end{tabular}

Table No 2: Comparison of male left vs female left jugular foramen

\begin{tabular}{ccccc}
\hline Variables & \multicolumn{2}{c}{$\begin{array}{c}\text { Jugular Foramen } \\
\text { length }\end{array}$} & \multicolumn{2}{c}{$\begin{array}{c}\text { Jugular foramen } \\
\text { width }\end{array}$} \\
\hline M ean & M & $\mathrm{F}$ & $\mathrm{M}$ & $\mathrm{F}$ \\
S.D. & 1.44 & 1.45 & 0.77 & 0.76 \\
t value & 0.22 & 0.34 & 0.19 & 0.18 \\
p value & \multicolumn{2}{c}{0.22} & \multicolumn{2}{c}{0.26} \\
\hline
\end{tabular}

Table no 3: Comparison of male right vs left jugular foramen Variables Jugular Foramen length Jugular foramen width

\begin{tabular}{|c|c|c|c|c|}
\hline & & & \\
\hline & Right & Left & Right & Left \\
\hline Mean & 1.75 & 1.44 & 0.98 & 0.77 \\
\hline S.D. & 0.23 & 0.22 & 0.20 & 0.19 \\
\hline t value & & & & \\
\hline$p$ value & & & & \\
\hline
\end{tabular}

Table 4: Comparison of female right vs left jugular foramen

\begin{tabular}{ccccc}
\hline Variables & \multicolumn{2}{c}{$\begin{array}{c}\text { Jugular Foramen } \\
\text { length }\end{array}$} & \multicolumn{2}{c}{ Jugular foramen width } \\
\hline & Right & Left & Right & Left \\
M ean & 1.71 & 1.45 & 0.93 & 0.76 \\
S.D. & 0.18 & 0.34 & 0.23 & 0.18 \\
t value & \multicolumn{2}{c}{3.95} & \multicolumn{2}{c}{3.41} \\
P value & & 0.00 & \multicolumn{2}{c}{0.16} \\
\hline
\end{tabular}

\section{RESULTS}

1. Length - the mean length of jugular foramen in male on right side was $1.75 \mathrm{~cm}$ and on left side $1.44 \mathrm{~cm}$ while in female the mean length was $1.71 \mathrm{~cm}$ on right side and $1.45 \mathrm{~cm}$ on left side. When compared with the length on right and left side by using $t$ test; $t$ value in male was 7.83 while in female it was 3.95. So the length of right jugular foramen was more than the left side and it is statistically significant.

2. Width- the mean width of jugular foramen in male on right side was $0.98 \mathrm{~cm}$ and on left side it was $0.77 \mathrm{~cm}$. In case of female the mean width on right side was $0.93 \mathrm{~cm}$ and on left side $0.76 \mathrm{~cm}$. Comparison of the length on right and left side in case of male 5.93 and in case of female it was 3.41. So the width of the right jugular foramen was more than the left side and it is statistically significant.

The tables showed the measurements and comparison of results of jugular foramina in the skulls included in the study, according to genders were tabulated. The data showed in table no 1 and 2, predicted that no significant differences in jugular foramina length and its width of male and female right and left sides. The dimensions of the jugular foramina of males and females depicted higher values in males as compared to females except the length of the jugular foramen on left side. The table no 3 and 4 showed comparison of male right and left ear, female right and left ear respectively, which showed right sided jugular foramina had significantly higher values as compared to left one.

\section{DISCUSSION}

The size and shape of the jugular foramen is much variable and is related to the size of internal jugular vein. The right jugular foramen is usually larger than the left but because of wide variations in the anatomy of structures passing through it accounts for the variation in size and shape of jugular foramen. The size of internal jugular vein is variable in right and left sides. It is already visible in the human embryo at the $23 \mathrm{~mm}$ stage and probably results from differences in the pattern of development of right and left brachiocephalic veins ${ }^{6}$. Rhoton et al (1975) studied the morphology of jugular foramen and they noted that $68 \%$ of jugular foramen was larger on right, $12 \%$ equal, $20 \%$ smaller ${ }^{7}$. In Sturrock's investigation of 156 skulls, the right foramen was larger in $68.6 \%$, the left larger in $23.1 \%$ and equal on both sides in $8.3 \%$. Hatiboglue and Anil studied 300 Antolian skulls from the $17^{\text {th }}$ and $18^{\text {th }}$ centuries and observed that in $61.6 \%$ the jugular foramen was larger on the right side and in $26 \%$ it was larger on the left side and in remainder of equal size ${ }^{8}$. Patel and Singel studied 91 Indian skulls 
and observed in $60.4 \%$ cases larger right foramen, in $15.4 \%$ larger left foramen and in $24.2 \%$ equal on both sides ${ }^{9}$. Hussain Saheb S et al (2010) studied the 250 jugular foramina and in 55\% cases right jugular foramen was larger while in $25 \%$ left jugular foramen was larger. In $20 \%$ cases it was equal on both sides ${ }^{6}$. In our study we observed larger right jugular foramen in $80 \%$, left foramen in $20 \%$ and it is equal in $1.5 \%$ cases in males. While in females right jugular foramen larger in $71 \%$, left larger in $28.57 \%$, and equal in $0.42 \%$ cases. Hovelacque was the first to propose the subdivision of jugular foramen. The foramen is divided by a fibrous or bony septum that joins the jugular spine of the petrous bone to the jugular process of the occipital bone into an anteromedial and a posteromedial compartment ${ }^{6}$. Tekdemir et al observed no partition in their studies while Ekinci et al found bony bridges in $20 \%$ and tripartite jugular foramen in $0.7 \%^{6}$. In Sturrock's investigation, he observed complete separation on right side in $3.2 \%$, on left side in $3.2 \%$ and partial separation on right side in $1.3 \%$ and partial separation on right side in $1.3 \%$ and on left side it was $10.9 \%^{10}$.

\section{CONCLUSION}

The jugular foramen contains significant vessels and neural structures. The present study observed that right jugular foramen is larger than the left one when studied on 100 dry skulls. Same was observed in previous studies done by various authors. These findings will be useful for neurosurgeons, radiologists and forensic experts.

\section{REFERENCES}

1. Standring S. Grays anatomy. 40 ed. Standring S, editor. Spain Elsevier; 2008.

2. Karen s. Caldemeyer VPM, Biago Azzarelli, Richard R. Smith. The jugular foramen: a review of anatomy, masses and imaging characteristics. Scientific exhibit. $1997 ; 17(5)$.

3. Christoph J. Griessenauer BM, Petru Matusz, Raffaele De Caro. Surgical approaches to the jugular foramen: A comprehensive review. J Neurol Surg. 2016;77:260-4.

4. Vikas C Desai PPH. A morphological study of jugular foramen Journal of pharmaceutical sciences and research. 2017;9(4):456-8.

5. Navasa N KBA. A quantitative assesment of the jugular foramen Anatomischer Anzeiger. 1998;180:269-73.

6. Hussain Saheb S MGF, Thomas S T, Prasanna L C< Muralidhar p. A morphometric study of the jugular foramen in human adult skulls of south India. J Biomed Sci and Res. 2010;2(4):240-3.

7. Albert L. Rhoton RB. Microsurgical anatomy of the jugular foramen. Journal of neurosurgery. 1975;42(5):541-50.

8. Hatiboglu M T AA. structural variations in the jugular foramen of the skulls. Journal of Anatomy. 1992;180:191-6.

9. Patel M M STC. Variations in the structure of the jugular foramen of the human skull in Saurashtra region. J Anat Soc India. 2007;56(2):34-7.

10. Sturrock RR. Variations in the structure of the jugular foramen of the human skull. Journal of Anatomy. 1998;160:227-30.

$$
\begin{aligned}
& \text { Source of Support: None Declared } \\
& \text { Conflict of Interest: None Declared }
\end{aligned}
$$

